\title{
Rock bolt supporting factor: rock bolting capability of rock mass
}

\author{
Mohammad Mohammadi $^{1} \cdot$ Mohammad Farouq Hossaini $^{2} \cdot$ Heydar Bagloo $^{3}$
}

Received: 22 June 2015/Accepted: 15 August 2015/Published online: 19 December 2015

(C) The Author(s) 2015. This article is published with open access at Springerlink.com

\begin{abstract}
Rock mass classification has played a crucial role in underground construction and mining projects in the past fifty years, especially the Rock Mass Rating (RMR) and Rock Tunneling Quality Index (Q) systems, which have been applied in many cases. The parameters of discontinuity conditions in the RMR system, along with the related ratings, were used to develop a new equation in order to introduce an intrinsic quality of a given rock mass, namely, rock bolt supporting factor (RSF). The RSF was used to develop a mathematical theory of the rock bolt supporting mechanism as a new principle in explaining rock bolting effects. Finally, using the parameters of the discontinuities in the Q-system, the QRSF is defined to present the capability of a given rock mass to be reinforced by rock bolting. The RSF leads to more reliable judgment of rock bolting capability of a given rock mass than the QRSF since it uses five parameters of discontinuity conditions while the QRSF uses only two parameters.
\end{abstract}

Keywords Rock bolt - Reinforcement capability - Rock mass classification $\cdot$ RMR $\cdot$ Q system

Mohammad Mohammadi

Mohammadisalmasi@yahoo.com

Mohammad Farouq Hossaini

mfarogh@ut.ac.ir

Heydar Bagloo

Hbagloo@aut.ac.ir

Tehran, Iran

2 School of Mining Engineering, University College of Engineering, University of Tehran, Tehran 14395-515, Iran

3 Amir Kabir University of Technology, Tehran, Iran

\section{Introduction}

Rock mass classifications form an integral part of the empirical design methods in mining and civil works which have provided the only systematic design aid in many cases of underground construction and mining projects (Bieniawsky 1989). The first rock engineering classification system was proposed for tunneling with steel ribs by Terzaghi (1946). In this method, rock loads on the steel sets can be estimated through a descriptive classification which categorizes rock masses into intact, stratified, moderately jointed, blocky and seamy, crushed, squeezing and, finally, swelling rock. Classification involving stand-up time was introduced by Lauffer (1958). He proposed that the quality of surrounding rock mass determines the stand-up time of unsupported spans of an excavation. An unsupported span is defined as the span of the tunnel or the distance between the face and nearest support, if this is greater than the tunnel span. Lauffer's original classification was modified by Pacher et al. (1974), leading to introduction of a general tunneling approach known as the New Austrian Tunneling Method (NATM).

Deere et al. (1967) developed a rock quality designation (RQD) index to provide a quantitative description of rock mass quality from drill core logs. The RQD is defined as the percentage of core pieces longer than $10 \mathrm{~cm}$ in the overall length of a core. In case where no cores are available but discontinuity traces can be seen, Palmstrom's (1982) equation (Eq. 1) for clay-free rock masses can be used to obtain RQD values where $J_{v}$ is the sum of the number of joints per unit length for all discontinuity sets, known as volumetric joint count.

$\mathrm{RQD}=115-3.3 J_{v}$

A quantitative method known as rock structure rating (RSR) was introduced by Wickham et al. (1972) in order 
to describe rock mass quality and select appropriate supporting systems based on this method. The RSR system was the first to feature classification ratings for weighting the relative importance of classification parameters. Numerical RSR values with a maximum of 100 can be obtained as a result of summing the ratings attributed to each component of the system, namely: A, B and $\mathrm{C}$ where $\mathrm{A}$ is related to geological rock mass features, B is related to geometry (effect of discontinuity pattern with regard to tunnel drive) and $\mathrm{C}$ represents the effect of groundwater with regard to joint conditions. After calculation of the RSR value, the supporting system for the tunnel can be estimated from curves proposed for this purpose.

Geomechanics classification, also known as the Rock Mass Rating (RMR) system, was developed by Bieniawsky (1973). As more case histories became available and to conform with international standards and procedures, the original RMR system was modified several times over the years. To classify a rock mass using the RMR system, six parameters, namely uniaxial compressive strength (UCS), rock quality designation (RQD), spacing of discontinuities, condition of discontinuities, groundwater conditions and orientation of discontinuities, are used (Bieniawsky 1989). This classification system will be thoroughly discussed since discontinuity conditions, as one of the input parameters in this classification system, are one of the main concerns in determining the rock bolt supporting factor (RSF) of a rock mass.

Using six parameters, namely RQD, number of joint sets, roughness of the most unfavorable joint or discontinuity, degree of alteration or filling along the weakest joint, water inflow and stress condition, Barton et al. (1974) defined the Rock Tunneling Quality Index (Q) as an equation two where the first quotient $\left(\mathrm{RQD} / J_{n}\right)$ represents the block size in the rock mass, the second quotient $\left(J_{r} / J_{a}\right)$ represents the roughness and frictional characteristics of the joint walls or filling materials, and the third quotient $\left(\mathrm{SRF} / J_{w}\right)$ consists of two stress parameters.

$Q=\frac{\mathrm{RQD}}{J_{n}} \frac{J_{r}}{J_{a}} \frac{J_{w}}{\mathrm{SRF}}$

In this paper, RSF is introduced as an intrinsic quality of a rock mass based on the condition of discontinuities in the RMR system. The RSF is also used to develop a mathematical theory on the rock bolting mechanism as well as some other applications which specify the capability of a given rock mass to be reinforced by rock bolting. Afterwards, a similar factor was developed based on the Q-system of rock mass classification, and the applicability of this factor is discussed.

\section{RMR: a theoretical excursion}

Geomechanics classification, also known as the RMR system, was developed by Bieniawsky (1973). However it has been subsequently modified several times and is mainly used as a design guideline in tunneling practices. Also, some valuable applications of the RMR system, as mentioned by Bieniawsky (1989), include: mining applications (Laubscher 1977, 1984); rippability (Weaver 1975); hard rock mining (Kendorski et al. 1983); coal mining (Unal 1983; Newman and Bieniawski 1986); dam foundations (Serafim and Pereira 1983); tunneling (Gonzalez de Vallejo 1983); slope stability (Romana 1985); and Indian coal mines (Venkateswarlu 1986).

The RMR system uses six parameters, namely: UCS, RQD, spacing of discontinuities, condition of discontinuities, groundwater conditions and orientation of discontinuities, to classify a rock mass. After establishing the importance ratings for these classification parameters, the ratings for the first five parameters are summed to yield the basic (unadjusted for discontinuity orientations) RMR value which varies from 0 to 100 . The sixth parameter (strike and dip orientation of discontinuities) is treated separately due to its dependency on engineering application of underground excavations such as mines, tunnels, slopes or foundations (Bieniawsky 1989).

The parameter 'condition of discontinuities' consists of five characteristics, each with a maximum rating of 6 . The maximum aggregate value of these 5 parameters is 30 , which is the maximum rating of discontinuity conditions. The aforementioned five parameters include discontinuity length (persistence/continuity), separation (aperture), roughness, infilling (gouge) and weathering. Guidelines for classification of discontinuity conditions is presented in Tables 1 and 2. The maximum allocated ratings for UCS (rating: 15), RQD (20), spacing of discontinuities (20), condition of discontinuities (30) and groundwater conditions (15) are summed to yield the maximum theoretical value of basic RMR as 100 . In determining the RSF, the sixth parameter of the RMR system, orientation of discontinuities, is not used because it's not an intrinsic property of a rock mass as defined with regard to the tunnel axis.

Different combinations of the parameters comprising the basic RMR to yield the values of 85, 74, 45 and 25 are shown in Tables 3, 4, 5 and 6, respectively. The main question here is whether there is any difference among the rock types described in states A to D of Table 3 while the RMR values are the same and, if so, what is the difference. These questions are also considerable for Tables 4, 5 and 6 which demonstrate the different combinations of input parameters to yield other basic RMR values in each case. 
Table 1 Guidelines for classification of discontinuity conditions (after Bieniawski 1989)

\begin{tabular}{|c|c|c|c|c|c|}
\hline Parameter & Ratings & & & & \\
\hline \multirow[t]{2}{*}{ Discontinuity length (persistence/continuity) } & $<1 \mathrm{~m}$ & $1-3 \mathrm{~m}$ & $3-10 \mathrm{~m}$ & $10-20 \mathrm{~m}$ & $>20 \mathrm{~m}$ \\
\hline & 6 & 4 & 2 & 1 & 0 \\
\hline \multirow[t]{2}{*}{ Separation (aperture) } & None & $<0.1 \mathrm{~mm}$ & $0.1-1 \mathrm{~mm}$ & $1-5 \mathrm{~mm}$ & $>5 \mathrm{~mm}$ \\
\hline & 6 & 5 & 4 & 1 & 0 \\
\hline \multirow[t]{2}{*}{ Roughness } & Very rough & Rough & Slightly rough & Smooth & Slickensided \\
\hline & 6 & 5 & 3 & 1 & 0 \\
\hline \multirow[t]{3}{*}{ Infilling (gouge) } & Hard filling & & & Soft filling & \\
\hline & None & $<5 \mathrm{~mm}$ & $>5 \mathrm{~mm}$ & $<5 \mathrm{~mm}$ & $>5 \mathrm{~mm}$ \\
\hline & 6 & 4 & 2 & 2 & 0 \\
\hline \multirow[t]{2}{*}{ Weathering } & Unweathered & Slightly weathered & Moderately weathered & Highly weathered & Decomposed \\
\hline & 6 & 5 & 3 & 1 & 0 \\
\hline
\end{tabular}

Some conditions are mutually exclusive. For example, if infilling is present, it is irrelevant what the roughness may be, since its effect will be overshadowed by the influence of the gouge. In such cases, Table 2 should be used directly.

Table 2 Guidelines for classification of discontinuity conditions (after Bieniawski 1989)

\begin{tabular}{llllll}
\hline $\begin{array}{l}\text { Condition of } \\
\text { discontinuities }\end{array}$ & $\begin{array}{l}\text { Very rough surfaces, } \\
\text { not continuous, no } \\
\text { separation, } \\
\text { unweathered wall } \\
\text { rock }\end{array}$ & $\begin{array}{l}\text { Slightly rough surfaces, } \\
\text { separation }<1 \mathrm{~mm}, \\
\text { slightly weathered walls }\end{array}$ & $\begin{array}{l}\text { Slightly rough } \\
\text { surfaces, separation } \\
<1 \mathrm{~mm} \text {, highly } \\
\text { weathered wall }\end{array}$ & $\begin{array}{l}\text { Slickensided surfaces or } \\
\text { gouge, }<5 \mathrm{~mm} \text { thick or } \\
\text { separation } 1-5 \mathrm{~mm} \\
\text { continuous }\end{array}$ & $\begin{array}{l}\text { Soft gouge }>5 \mathrm{~mm} \\
\text { thick or separation } \\
>5 \mathrm{~mm} \text { continuous }\end{array}$ \\
\hline Rating & 30 & 25 & 20 & 10 & 0 \\
\hline
\end{tabular}

The key issue to consider is the point of view from which these rock types are being viewed. For example, to assess the rock mass quality for tunneling and stability purposes, there may be no difference between the rock masses with the same RMR values with different combinations of parameters. However, considering the reinforcement capability of rock mass by rock bolting or grout injection practices, there is a considerable difference between these rock masses as the discontinuity conditions differ in each case. These differences will be explained and formulated as the RSF, which indicates the intrinsic capability of a given rock mass to be reinforced by rock bolting.

\section{RSF}

The RMR value for a type of rock mass which has no discontinuity sets will be dependent on the UCS, ranging from 85 to 100 and fitting into class I of the RMR classification. So is the RMR value of completely dry rock masses with an RQD value of $100 \%$, spacing of discontinuities more than $2000 \mathrm{~mm}$ and condition of discontinuities being as column 2 of Table 1 (overall rating of 30). Therefore, the existence of discontinuities in case 2 has no effect on the reduction of the RMR value for the supposed rock mass. This is due to the RMR system focusing on the behavior of discontinuities and their contribution to the rock mass behavior.

Paying close attention to the details of discontinuity conditions, as presented in Table 1, reveals the fact that the ratings for each parameter are allocated according to the degree of its participation in the increase of shear resistance of the discontinuity surface. For instance, very rough surfaces will cause more resistance than smooth surfaces due to which the rating for very rough surfaces is more than that of smooth surfaces. Also, tight discontinuities have more impact than open ones, the existence of infilling material will cause decrease of shear resistance, and unweathered surfaces have more ratings than decomposed ones. A lower persistence of discontinuities means a lower decrease of shear resistance. Regarding this point, increasing the friction of discontinuity surfaces can cause a noticeable impact on the reinforcement of rock masses.

A properly designed rock bolting system, precluding rock blocks from sliding due to increased shear resistance of the discontinuity surfaces, can cause an increase in the rating of discontinuity condition parameters, namely persistence, aperture, roughness, infilling and weathering, from their initial values to maximum values of 6 , the sum of which produces the maximum aggregate rating of 30 for 
Table 3 Different combinations of parameters to yield the basic RMR value of 85

\begin{tabular}{|c|c|c|c|c|}
\hline $\begin{array}{l}\text { State } \\
\text { Parameter }\end{array}$ & $\begin{array}{l}\mathrm{A} \\
\mathrm{RMR}=85\end{array}$ & $\begin{array}{l}\mathrm{B} \\
\mathrm{RMR}=85\end{array}$ & $\begin{array}{l}\mathrm{C} \\
\mathrm{RMR}=85\end{array}$ & $\begin{array}{l}\mathrm{D} \\
\mathrm{RMR}=85\end{array}$ \\
\hline \multicolumn{5}{|l|}{ UCS (Mpa) } \\
\hline Value & 260 & 260 & 110 & 260 \\
\hline Rating & 15 & 15 & 10 & 15 \\
\hline \multicolumn{5}{|l|}{ RQD (\%) } \\
\hline Value & 85 & 90 & 100 & 100 \\
\hline Rating & 17 & 18 & 20 & 20 \\
\hline \multicolumn{5}{|l|}{ Spacing } \\
\hline Value & $200 \mathrm{~mm}$ & $650 \mathrm{~mm}$ & $2200 \mathrm{~mm}$ & $2200 \mathrm{~mm}$ \\
\hline Rating & 8 & 12 & 20 & 20 \\
\hline \multicolumn{5}{|c|}{ Condition of discontinuities } \\
\hline \multicolumn{5}{|c|}{ Persistence } \\
\hline Value & $<1 \mathrm{~m}$ & $1-3 \mathrm{~m}$ & Slightly rough surfaces & $10-20 \mathrm{~m}$ \\
\hline Rating & 6 & 4 & Separation $<1 \mathrm{~mm}$ & 1 \\
\hline Aperture & & & Highly weathered wall & \\
\hline Value & None & $<0.1 \mathrm{~m}$ & & $0.1-1 \mathrm{~mm}$ \\
\hline Rating & 6 & 5 & & 4 \\
\hline \multicolumn{5}{|l|}{ Roughness } \\
\hline State & Very rough & Rough & & Smooth \\
\hline Rating & 6 & 5 & & 3 \\
\hline \multicolumn{5}{|l|}{ Infilling } \\
\hline Value & None & None & & None \\
\hline Rating & 6 & 6 & & 6 \\
\hline \multicolumn{5}{|c|}{ Weathering } \\
\hline State & Unweathered & Slightly weathered & & Highly weathered \\
\hline Rating & 6 & 5 & 20 & 1 \\
\hline \multicolumn{5}{|c|}{ Groundwater [inflow per 10 meter tunnel length $(\mathrm{L} / \mathrm{min})$ ] } \\
\hline State & Completely dry & Completely dry & Completely dry & Completely dry \\
\hline Rating & 15 & 15 & 15 & 15 \\
\hline
\end{tabular}

condition of discontinuities. In fact, a properly designed rock bolting system does not eliminate the aperture, persistence or other characteristics of discontinuities. However, it increases the shear resistance of discontinuities to their maximum and since the RMR ratings are interested in the shear behavior of discontinuities, it is reasonable to consider the complex of rock mass and rock bolts as an equivalent rock mass with the overall discontinuity rating of 30. For example, the overall rating of discontinuity conditions in state $\mathrm{C}$ of Table 3 (which is 20) can be increased 10 points to reach the maximum of 30 . Therefore, the increase of 10 points is the capability of the rock mass to be reinforced by rock bolting. These values for states A, B and D of Table 3 are 0,5 and 15, respectively. Therefore, the capability of a rock mass to be reinforced can be defined as a percent of the overall discontinuity condition rating. This definition is presented as Eq. 3 where $r_{\mathrm{co}}$ is the overall rating for the condition of discontinuities. The results are multiplied by 100 to be in accordance with the RMR values and the mathematical [] sign was used to omit the decimal part of the obtained values, which can range from 0 (for $r_{\text {co }}=30$ ) to 100 (for $r_{\text {co }}=0$ ) where RSF $=100$ shows the greatest capability of a given rock mass to be reinforced by rock bolting.

$\mathrm{RSF}=\left[100 \times \frac{30-r_{\mathrm{co}}}{30}\right]$

Equation 3 can be rewritten as Eq. 4.

$\mathrm{RSF}=\left[100-\frac{10 \times r_{\mathrm{co}}}{3}\right]$

RSF is an intrinsic property of a given rock mass which can be used to explain the difference of rock types with the same RMR values presented in Tables 3-6. Table 7 shows the RSF values for the aforementioned rock types. A higher RSF value for a given rock mass indicates a greater ability 
Table 4 Different combinations of parameters to yield the basic RMR value of 74

\begin{tabular}{|c|c|c|c|c|c|}
\hline $\begin{array}{l}\text { State } \\
\text { Parameter }\end{array}$ & $\begin{array}{l}\mathrm{A} \\
\mathrm{RMR}=74\end{array}$ & $\begin{array}{l}\mathrm{B} \\
\mathrm{RMR}=74\end{array}$ & $\begin{array}{l}\mathrm{C} \\
\mathrm{RMR}=74\end{array}$ & $\begin{array}{l}\mathrm{D} \\
\mathrm{RMR}=74\end{array}$ & $\begin{array}{l}\mathrm{E} \\
\mathrm{RMR}=74\end{array}$ \\
\hline \multicolumn{6}{|c|}{ UCS (Mpa) } \\
\hline Value & 68 & 125 & 80 & 200 & 165 \\
\hline Rating & 7 & 11 & 8 & 14 & 13 \\
\hline \multicolumn{6}{|l|}{ RQD (\%) } \\
\hline Value & 95 & 80 & 100 & 100 & 100 \\
\hline Rating & 19 & 16 & 20 & 20 & 20 \\
\hline \multicolumn{6}{|l|}{ Spacing } \\
\hline Value & $500 \mathrm{~mm}$ & $300 \mathrm{~mm}$ & $2200 \mathrm{~mm}$ & $1100 \mathrm{~mm}$ & $2200 \mathrm{~mm}$ \\
\hline Rating & 11 & 9 & 20 & 15 & 20 \\
\hline \multicolumn{6}{|c|}{ Condition of discontinuities } \\
\hline \multicolumn{6}{|c|}{ Persistence } \\
\hline Value & $<1 \mathrm{~m}$ & $1-3 \mathrm{~m}$ & $3-10 \mathrm{~m}$ & Slickensided surfaces or gouge $<5 \mathrm{~mm}$ & $>20 \mathrm{~m}$ \\
\hline Rating & 6 & 4 & 2 & thick or separation $1-5 \mathrm{~mm}$ continuous & 0 \\
\hline \multicolumn{6}{|l|}{ Aperture } \\
\hline Value & None & $<0.1 \mathrm{~mm}$ & $0.1-1 \mathrm{~mm}$ & & $>5 \mathrm{~mm}$ \\
\hline Rating & 6 & 5 & 4 & & 0 \\
\hline \multicolumn{6}{|l|}{ Roughness } \\
\hline State & Very rough & Slightly rough & Smooth & & Slickensided \\
\hline Rating & 6 & 3 & 1 & & 0 \\
\hline \multicolumn{6}{|l|}{ Infilling } \\
\hline Value & None & None & None & & None \\
\hline Rating & 6 & 6 & 6 & & 6 \\
\hline \multicolumn{6}{|c|}{ Weathering } \\
\hline State & Unweathered & Slightly weathered & Moderately weathered & & Decomposed \\
\hline Rating & 6 & 5 & 3 & 10 & 0 \\
\hline \multicolumn{6}{|c|}{ Groundwater [inflow per 10 meter tunnel length $(\mathrm{L} / \mathrm{min})$ ] } \\
\hline State & Wet & Completely dry & Damp & Completely dry & Completely dry \\
\hline Rating & 7 & 15 & 10 & 15 & 15 \\
\hline
\end{tabular}

to be reinforced by rock bolting. Nevertheless, it should be noticed that higher RSF values mean a greater load affecting the rock bolts, requiring a enhanced rock bolting efficiency. This idea was used in the Alborz Tunnel of Iran to determine whether to install rock bolts or shotcrete in cases where there was a necessity to proceed with the next round of excavation without completing the support system, as described in the RMR system, to achieve the monthly advance rate. It should be noticed that the type of rock bolts implemented is not a key factor as long as the design is properly carried out since the RSF is an intrinsic property of a rock mass and depends on the condition of discontinuities rather than the type of rock bolts. Figure 1 shows the relationship between RMR and RSF for different rock types presented in Table 7. As is obvious, RSF generally decreases with increased RMR values.

\section{Mechanism of rock bolting}

The mechanism of rock bolting has not been fully understood due to the existence of many varying properties of bolts and rocks. Four cases were studied by Habenicht (1983) in order to explain some of the important bearing capacity mechanisms of rock bolting; the cases are summarized as suspending, nailing, beam building and arch building effects. These effects are shown in Fig. 2. A designed rock bolting system must meet certain requirements on the basis of at least one of the aforementioned four effects. However, sometimes in cases with complex conditions, more than one effect is considered.

Benefiting from the concept of reinforcement by rock bolting, a fifth principle of bolting can be introduced. As mentioned in previous sections, the principle is very 
Table 5 Different combinations of parameters to yield the basic RMR value of 45

\begin{tabular}{|c|c|c|c|c|c|c|}
\hline $\begin{array}{l}\text { State } \\
\text { Parameter }\end{array}$ & $\begin{array}{l}\mathrm{A} \\
\mathrm{RMR}=45\end{array}$ & $\begin{array}{l}\mathrm{B} \\
\mathrm{RMR}=45\end{array}$ & $\begin{array}{l}\mathrm{C} \\
\mathrm{RMR}=45\end{array}$ & $\begin{array}{l}\mathrm{D} \\
\mathrm{RMR}=45\end{array}$ & $\begin{array}{l}\mathrm{E} \\
\mathrm{RMR}=45\end{array}$ & $\begin{array}{l}\mathrm{F} \\
\mathrm{RMR}=45\end{array}$ \\
\hline \multicolumn{7}{|l|}{ UCS (Mpa) } \\
\hline Value & 68 & 80 & 110 & 140 & 260 & 80 \\
\hline Rating & 7 & 8 & 10 & 12 & 15 & 8 \\
\hline \multicolumn{7}{|l|}{ RQD (\%) } \\
\hline Value & 30 & 30 & 40 & 40 & 60 & 95 \\
\hline Rating & 7 & 7 & 8 & 8 & 12 & 19 \\
\hline \multicolumn{7}{|c|}{ Spacing $(\mathrm{mm})$} \\
\hline Value & 50 & 50 & 100 & 200 & 200 & 500 \\
\hline Rating & 6 & 6 & 8 & 8 & 8 & 11 \\
\hline \multicolumn{7}{|c|}{ Condition of discontinuities } \\
\hline \multicolumn{7}{|c|}{ Persistence } \\
\hline Value & $1-3 \mathrm{~m}$ & $3-10 \mathrm{~m}$ & $10-20 \mathrm{~m}$ & $10-20 \mathrm{~m}$ & $>20 \mathrm{~m}$ & Soft gouge $>5 \mathrm{~mm}$ thick \\
\hline Rating & 4 & 2 & 1 & 1 & 0 & or \\
\hline Aperture & & & & & & Separation $>5 \mathrm{~mm}$ \\
\hline Value & $0.1-1 \mathrm{~mm}$ & $0.1-1 \mathrm{~mm}$ & $0.1-1 \mathrm{~mm}$ & $1-5 \mathrm{~mm}$ & $>5 \mathrm{~mm}$ & continuous \\
\hline Rating & 4 & 4 & 4 & 1 & 0 & \\
\hline \multicolumn{7}{|l|}{ Roughness } \\
\hline State & Very rough & Slightly rough & Smooth & Smooth & Slickensided & \\
\hline Rating & 6 & 3 & 1 & 1 & 0 & \\
\hline \multicolumn{7}{|l|}{ Infilling } \\
\hline Value & None & None & None & None & None & \\
\hline Rating & 6 & 6 & 6 & 6 & 6 & \\
\hline \multicolumn{7}{|c|}{ Weathering } \\
\hline State & $\begin{array}{l}\text { Slightly } \\
\text { weathered }\end{array}$ & $\begin{array}{l}\text { Slightly } \\
\text { weathered }\end{array}$ & $\begin{array}{l}\text { Moderately } \\
\text { weathered }\end{array}$ & $\begin{array}{l}\text { Highly } \\
\text { weathered }\end{array}$ & Decomposed & \\
\hline Rating & 5 & 5 & 3 & 1 & 0 & 0 \\
\hline \multicolumn{7}{|c|}{ Groundwater [inflow per 10 meter tunnel length $(\mathrm{L} / \mathrm{min})$ ] } \\
\hline State & Flowing & Dripping & Dripping & Wet & Dripping & Wet \\
\hline Rating & 0 & 4 & 4 & 7 & 4 & 7 \\
\hline
\end{tabular}

simple: rock bolting increases the discontinuity rating to its maximum in the RMR system, whereby it can be supposed that the RMR value of a rock mass also increases. Therefore, after rock bolting, the behavior of a complex of rock masses and bolts can be assumed as a new rock mass with the increased RMR value based on the rock bolting capability of the original rock mass. The RMR value of the complex of rock masses and bolts is the fifth rock bolting effect which is going to be mentioned the as 'equivalent RMR' or ' $R M R_{\text {eq }}$ '. The amount of increase in the RMR value to obtain the equivalent RMR is simply computed using Eq. 5 .

$\mathrm{RMR}_{\mathrm{eq}}-\mathrm{RMR}=30-r_{\mathrm{co}}$

To formulate the fifth principle of rock bolting, the RSF is used in order to gain $\mathrm{RMR}_{\mathrm{eq}}$, as shown in Eq. 6, which can easily be concluded from Eqs. 5 and 3.

$\mathrm{RMR}_{\mathrm{eq}}=\mathrm{RMR}+0.3 \mathrm{RSF}$
Equation 6 is the mathematical definition of the fifth rock bolting principle, the importance of which is due to its form as a mathematical equation rather than simply being in an explanatory form. It should be noticed that any decimal value obtained for $\mathrm{RMR}_{\mathrm{eq}}$ should be rounded up to give the exact value of $\mathrm{RMR}_{\mathrm{eq}}$ as the mathematical [] sign was used to obtain the value of RSF. For instance, the obtained value for $\mathrm{RMR}_{\mathrm{eq}}$ of state $\mathrm{B}$ in Table 3 is 89.8 which must be rounded up to yield the value of 90 for an equivalent RMR value.

\section{RSF and the Q-system}

The Q-system uses only two joint condition parameters, namely joint roughness $\left(J_{r}\right)$ and joint alteration $\left(J_{a}\right)$. The quotient of these parameters $\left(J_{r} / J_{a}\right)$ represents the roughness and frictional characteristics of joint walls or filling 
Table 6 Different combinations of parameters to yield the basic RMR value of 25

\begin{tabular}{|c|c|c|c|c|c|}
\hline $\begin{array}{l}\text { State } \\
\text { Parameter }\end{array}$ & $\begin{array}{l}\mathrm{A} \\
\mathrm{RMR}=25\end{array}$ & $\begin{array}{l}\mathrm{B} \\
\mathrm{RMR}=25\end{array}$ & $\begin{array}{l}\mathrm{C} \\
\mathrm{RMR}=25\end{array}$ & $\begin{array}{l}\mathrm{D} \\
\mathrm{RMR}=25\end{array}$ & $\begin{array}{l}\mathrm{E} \\
\mathrm{RMR}=25\end{array}$ \\
\hline \multicolumn{6}{|c|}{ UCS (Mpa) } \\
\hline Value & 20 & 20 & 20 & 20 & 55 \\
\hline Rating & 3 & 3 & 3 & 3 & 6 \\
\hline \multicolumn{6}{|l|}{ RQD (\%) } \\
\hline Value & 10 & 20 & 10 & 10 & 10 \\
\hline Rating & 4 & 5 & 4 & 4 & 4 \\
\hline \multicolumn{6}{|c|}{ Spacing (mm) } \\
\hline Value & 30 & 50 & 30 & 30 & 30 \\
\hline Rating & 5 & 6 & 5 & 5 & 5 \\
\hline \multicolumn{6}{|c|}{ Condition of discontinuities } \\
\hline \multicolumn{6}{|c|}{ Persistence } \\
\hline Value & $3-10 \mathrm{~m}$ & $>20 \mathrm{~m}$ & $10-20 \mathrm{~m}$ & $>20 \mathrm{~m}$ & Soft gouge $>5 \mathrm{~mm}$ thick \\
\hline Rating & 2 & 0 & 1 & 0 & or \\
\hline Aperture & & & & & Separation $>5 \mathrm{~mm}$ continuous \\
\hline Value & $1-5 \mathrm{~mm}$ & $1-5 \mathrm{~mm}$ & $1-5 \mathrm{~mm}$ & $>5 \mathrm{~mm}$ & \\
\hline Rating & 1 & 1 & 1 & 0 & \\
\hline \multicolumn{6}{|c|}{ Roughness } \\
\hline State & Smooth & Smooth & Slickensided & Slickensided & \\
\hline Rating & 1 & 1 & 0 & 0 & \\
\hline \multicolumn{6}{|l|}{ Infilling } \\
\hline Value & None & None & None & None & \\
\hline Rating & 6 & 6 & 6 & 6 & \\
\hline \multicolumn{6}{|c|}{ Weathering } \\
\hline State & Moderately weathered & Moderately weathered & Highly weathered & Decomposed & \\
\hline Rating & 3 & 3 & 1 & 0 & 0 \\
\hline \multicolumn{6}{|c|}{ Groundwater [inflow per 10 meter tunnel length $(\mathrm{L} / \mathrm{min})$ ] } \\
\hline State & Flowing & Flowing & Dripping & Wet & Damp \\
\hline Rating & 0 & 0 & 4 & 7 & 10 \\
\hline
\end{tabular}

Table 7 RSF values for different rock types of Tables 3, 4, 5 and 6

\begin{tabular}{|c|c|c|c|c|c|c|}
\hline State & A & $\mathrm{B}$ & $\mathrm{C}$ & $\mathrm{D}$ & $\mathrm{E}$ & $\mathrm{F}$ \\
\hline \multicolumn{7}{|c|}{ Rock types presented in Table 3} \\
\hline RMR & 85 & 85 & 85 & 85 & - & - \\
\hline RSF & 0 & 16 & 33 & 50 & - & - \\
\hline \multicolumn{7}{|c|}{ Rock types presented in Table 4} \\
\hline RMR & 74 & 74 & 74 & 74 & 74 & - \\
\hline RSF & 0 & 23 & 46 & 66 & 80 & - \\
\hline \multicolumn{7}{|c|}{ Rock types presented in Table 5} \\
\hline RMR & 45 & 45 & 45 & 45 & 45 & 45 \\
\hline RSF & 16 & 33 & 50 & 66 & 80 & 100 \\
\hline \multicolumn{7}{|c|}{ Rock types presented in Table 6} \\
\hline RMR & 25 & 25 & 25 & 25 & 25 & - \\
\hline RSF & 56 & 63 & 70 & 80 & 100 & - \\
\hline
\end{tabular}

material. To define the rock bolting capability of a rock mass using the Q-system, these two parameters must be employed. Based on the Q-system, the $\mathrm{J}_{\mathrm{r}}$ values differ from
0.5 to 4 for different discontinuity conditions, whereas the $J_{a}$ values range from 0.75 to 20 . Therefore, the values of the quotient $J_{r} / J_{a}$ will range from 0.025 to 5.33 . It can be 


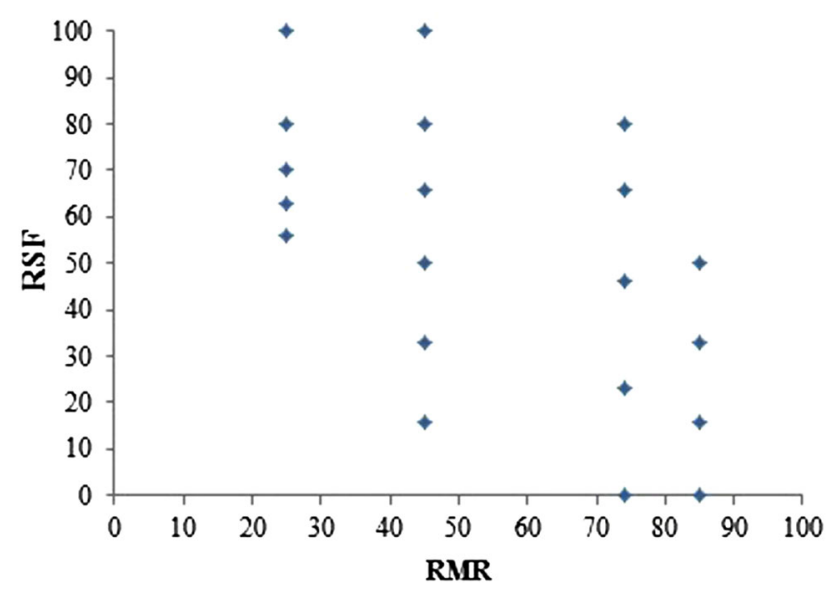

Fig. 1 RSF vs. RMR

assumed that the proper design and installation of a rock bolting system increases the value of this quotient from its initial value to its maximum of 5.33. Therefore, the amount of increase in the frictional characteristics of discontinuities $\left(I_{\mathrm{fc}}\right)$ can be calculated simply by using Eq. 7.

$I_{\mathrm{fc}}=5.33-\frac{J_{r}}{J_{a}}$

As presented in Eq. 8, the percent of reinforcement obtained by rock bolting can be computed. In order to be in accordance with the values of Q-system, the results have been multiplied by 1000 . The QRSF values range from 4.71 to 1004.71 .

$\mathrm{QRSF}=1000 \times \frac{I_{\mathrm{fc}}}{5.305}$

A value of 5.305 is obtained from the difference of maximum and minimum values of the quotient $J_{r} / J_{a}$ $(5.33-0.025=5.305)$. Equation 8 can be rewritten as Eq. 9.

$\mathrm{QRSF}=188.5 \times I_{\mathrm{fc}}$

Assuming that the proper design and implementation of the rock bolting system causes the $\mathrm{Q}$ value of rock mass to increase, the obtained value of $\mathrm{Q}$ for the combination of rock mass and rock bolting system (equivalent $\mathrm{Q}$ ) can be calculated using Eq. 10, which is easily been derived from Eqs. 2, 7, 8 and 9.

$Q_{\text {eq }}=\frac{5.33 \times Q}{5.33-\frac{\mathrm{QRSF}}{188.5}}$

The basic RMR and Q values in the Park River tunnel, as mentioned by Bieniawski (1989), were 56 and 9 , respectively, where the overall rating of discontinuities for the RMR system was 25 . The joints were rough, planar, unaltered walls with staining to which $\mathrm{J}_{\mathrm{r}}$ and $\mathrm{J}_{\mathrm{a}}$ values of 1.5 and 1, respectively, were allocated. The RSF value for this rock mass would be 16 whereas the QRSF value will be 722. As is obvious from the RSF value, the capability of

Fig. 2 Bolting principles (after Larsson 1984)

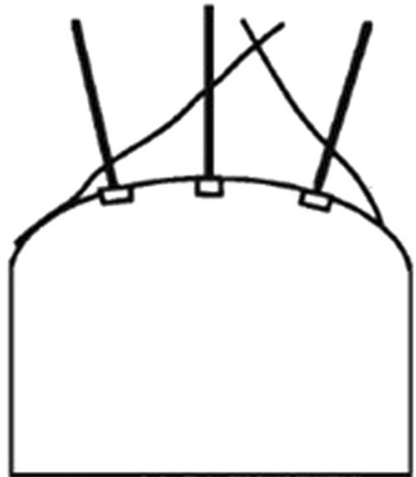

(a) Suspension effect

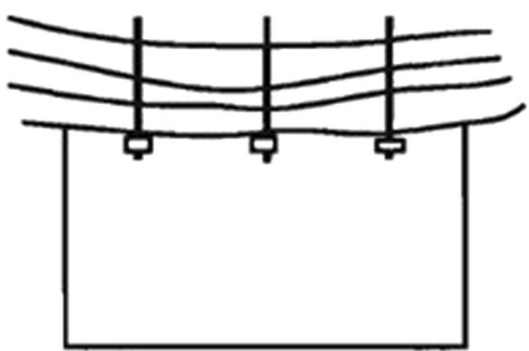

(c) Beam building effect

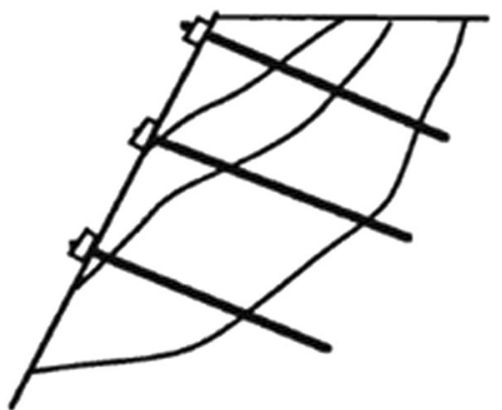

(b) Nailing effect

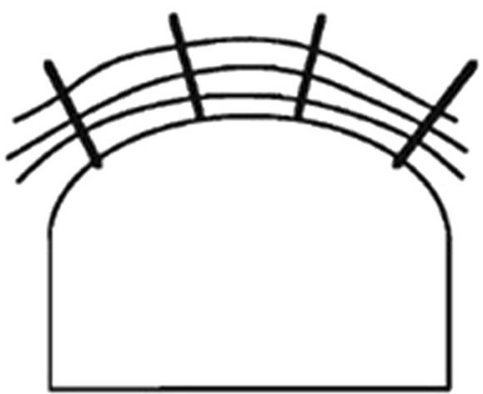

(d) Arch building effect 
this rock mass to be reinforced by rock bolting is rather low. However, the QRSF value suggests a rather high capacity for the rock mass to be reinforced by rock bolting. Thus, the QRSF value demonstrates an inability to generate an accurate assessment of the rock bolting capability of a rock mass. This is because the Q-system and, subsequently, the QRSF equation, use only two parameters of discontinuity conditions, which leads to a poorer assessment of the rock bolting capability of a rock mass. The equivalent RMR and Q for this rock mass are 61 and 32, respectively. Therefore, the rock bolting practice upgraded the rock mass condition from fair to good in both systems. However, the QRSF leads to poorer assessments of the rock bolting capability of a rock mass.

\section{Conclusions}

Based on the condition of discontinuities in the RMR system, an equation was developed to compute the capability of a given rock mass to be reinforced by a rock bolting system. Using the RSF, a mathematical approach was introduced to explain the mechanism of rock bolting as a new principle.

Finally, a similar approach was developed based on the Q-system which has been named QRSF. The RSF proved to be more reliable than the QRSF in assessing the rock bolting capability of a rock mass by employing five parameters of discontinuity conditions rather than two parameters in the QRSF.

Open Access This article is distributed under the terms of the Creative Commons Attribution 4.0 International License (http://crea tivecommons.org/licenses/by/4.0/), which permits unrestricted use, distribution, and reproduction in any medium, provided you give appropriate credit to the original author(s) and the source, provide a link to the Creative Commons license, and indicate if changes were made.

\section{References}

Barton N, Lien R, Lunde J (1974) Engineering classification of rock masses for the design of tunnel support. Rock Mech 6:183-236

Bieniawsky ZT (1973) Engineering classification of jointed rock masses. Trans S Afr Inst Civ Eng 15:335-344

Bieniawsky ZT (1989) Engineering rock mass classification: a complete manual for engineers and geologists in mining, civil and petroleum engineering. Wiley-Interscience publication, New York
Deere DU, Hendron AJ, Patton FD, Cording EJ (1967) Design of surface and near surface construction in rock. In: proceedings of 8th US symposium Rock Mechanics, AIME, New York, pp 237-302

Gonzalez de Vallejo LI (1983) A new rock classification system for underground assessment using surface data. In: Proceedings of International Symposium Engineering Geology Underground Construction, LNEC, Lisbon, vol. 1, pp II.85-II.94

Habenicht H (1983) The anchoring effects-our present knowledge and its shortcomings - a keynote lecture. In: proceedings of International Symposium on Rock Bolting, Abisko, pp 253-268

Kendorski F, Cummings R, Bieniawski ZT, Skinner E (1983) Rock mass classification for block caving mine drift support. In: Proceedings of 5th International Congress Rock Mechanics, ISRM, Melbourne, pp B51-B63

Larsson H (1984) Modeling of bolt action in jointed rock. Licenciate thesis, Lulea University, Sweden

Laubscher DH (1977) Geomechanics classification of jointed rock masses-mining applications. Trans Inst Min Metall 86:A1-A7

Laubscher DH (1984) Design aspects and effectiveness of support systems in different mining situations. Trans Inst Min Metall 93:A70-A81

Lauffer H (1958) Gebirgsklassifizierung für den Stollenbau. Geol Bauwesen 74:46-51

Newman DA, Bieniawski ZT (1986) Modified version of the Geomechanics classification for entry design in underground coal mines. Trans Soc Min Eng AIME 280:2134-2138

Pacher F, Rabcewicz L, Golser J (1974) Zum der seitigen Stand der Gebirgs-klassifizierung in Stollen-und Tunnelbau, proc. XXII Geomech Colloq, Salzburg, pp 51-58

Palmstrom A (1982) The volumetric joint count—a useful and simple measure of the degree of rock jointing. In: proceedings of 14th international congress, International Association Engineering Geology, Delhi, vol 5, pp 221-228

Romana M (1985) New adjustment ratings for application of Bieniawski classification to slopes. In: Proceedings of International Symposium Rock Mechanics in Excavation for Mining Civil Works, ISRM, Mexico City, pp 59-68

Serafim JL, Pereira JP (1983) Considerations of the Geomechanics classification of Bieniawski. In: Proceedings International Symposium Engineering Geology Underground Construction, LNEC, Lisbon, vol. 1, pp I.33-II.42

Terzaghi K (1946) Rock defects and loads on tunnel support. In: Proctor RV, White T (eds) Rock tunneling with steel supports. Commercial Shearing Co, Youngstown

Unal E (1983) Design guidelines and roof control standards for coal mine roofs. Ph.D. thesis, Pennsylvania State University, University park, p 355

Venkateswarlu V (1986) Geomechanics classification of coal measure rocks vis-à-vis roof supports. In: Ph.D. thesis, Indian school of mines, Dhanbad, p 251

Weaver J (1975) Geological factors significant in the assessment of rippability. Civ Eng S Afr 17(12):313-316

Wickham GE, Tiedemann HR, Skinner EH (1972) Support determination based on geologic predictions, In: Lane KS, Garfield LA (eds) Proceedings North American rapid excavation tunneling conference, Chicago, pp 43-64, New York: Soc Min Eng Am Inst Min Metall Petroleum Eng 